\title{
A SPECIES-SPECIFIC PCR ASSAY BASED ON THE INTERNAL TRANSCRIBED SPACER (ITS) REGIONS FOR IDENTIFICATION OF Mycosphaerella eumusae, $M$. fijiensis AND M. musicola ON BANANA
}

\author{
IMAN HIDAYAT \\ Microbiology Division, Research Center for Biology, Indonesian Institute of Sciences (LIPI), \\ Cibinong 16911, West Java, Indonesia
}

Recipient of BIOTROP Research Grant 2010/Accepted 28 June 2012

\begin{abstract}
A study on development of a rapid PCR-based detection method based on ITS region of $M$. eumusae, $M$. fijiensis, and $M$. musicola on banana was carried out. The main objecive of this study was to develop a fast and species-specific PCR-based detection method for the presence of Mycosphaerella species on banana. The methods include collection of specimens, morphological identification supported by molecular phylogenetic analysis, RFLP analysis, species-specific primers development, and validation. Two species of Mycosphaerella, namely, $M$. fijiensis and M. musicola, and one unidentified Pseudocercospora species were found in Java Island. Three restriction enzymes used in the RFLP analysis, viz, AluI, HaeIII, and TaqI were capable to discriminate $M$. eumusae, $M$. fijiensis, and $M$. musicola. Two species-specific primer pairs, viz, MfijF/MfijR and MmusF/MmusR have been successfully developed to detect the presence of $M$. fijiensis and M. musicola, respectively.
\end{abstract}

Key words: banana, detection, fungi, Mycosphaerella leaf spot, phytopathology

\section{INTRODUCTION}

Indonesia is one of banana production zones in Southeast Asia. However, crop losses from global climate change and fungal pathogens pose a serious threat not only to Indonesia, but also to global food security. Therefore, these threats should not be underestimated. Among the banana pathogens, three morphologically similar species, viz, Mycosphaerella fijiensis (black leaf streak disease/black Sigatoka), M. musicola (yellow Sigatoka disease), and $M$. eumusae (Eumusae leaf spot) are well known as important plant pathogens (Crous \& Mourichon 2002). In Indonesia, these pathogens are considered as quarantine organisms (http://www.karantina.deptan.go.id/optk/

*Corresponding author : imanhidayat@yahoo.com 
detail.php?id=731). Therefore, it is important to prevent introduction (entry and establishment) and to limit dissemination of these pathogens in many Indonesian banana-producing regions.

Correct and rapid identification is a fundamental step for limiting the dissemination of the plant pathogens (Arzanlou et al. 2007). Failure to manage the pathogens would have far reaching effects on the industry. The 10-14 days incubation and classical isolation of the pathogens by culturing on appropriate media followed by morphological characters examination is a standard method currently used in Indonesia for the imported crops inspection. However, an accurate detection and diagnosis of the $M$. fijiensis, $M$. musicola, and $M$. exmusae based on the conventional method are complicated due to the similarity in morphological characters (Arzanlou et al. 2007). Consequently, this problem yield difficulties for Indonesian quarantine in inspecting imported banana seeds or crops.

Many PCR-detection methods for fungi have shown to be accurate and sensitive in detection various plant pathogens (Bonants et al. 1997; Mumford et al. 2006). ITS sequence analysis has shown that $M$. fijiensis, M. musicola, and M. eumusae are only distantly related in terms of phylogeny (Crous et al. 2002). However, the phylogeny method was still time consuming and lacked specificity to differentiate among the M. fijiensis, M. musicola, and M. eumusae (Arzanlou et al. 2007). The lack of specificity was possibly due to the high variability among those three pathogens. Therefore, it is necessary to develop a fast and specific PCR-based detection method with the aim of improving the specificity of the diagnostic procedure and increasing throughout readiness for outbreaks of the disease.

\section{MATERIALS AND METHOD}

\section{Fungal materials}

Fungal materials were collected from several locations in Bogor and Cibinong (West Java), and one specimen was collected from Wonosobo (Central Java). Specimens with black leaf streak diseases symptoms of $M$. fijiensis were collected during the course of field trips by using a $10 \times / 20 \times$ magnifying lens. Specimens were kept in resealable plastic bag. The bags were labelled by adding all necessary information such as location, collector/s, collection date, host name, etc. Microscopic examination of materials was referred to Hidayat et al. (2007). Ascomata appearances of Mycosphaerella spp. and caespituli of anamorphic states (Pseudocercospora spp.) on the host surface were observed by using stereo microscope (OLYMPUS SZX7). Detailed observations of morphological characters was carried out by means of an OLYMPUS CX31 light microscope using oil immersion $(1000 \times)$. Water and lactophenol were used as mounting media. Measurements of all important characters and photographing/line drawings were conducted at a magnification of $1000 \times$. Single spore isolation was referred to Choi et al. (1999). Voucher specimens were deposited at the Herbarium Bogoriense, Research Center for Biology, Indonesian Institute of Sciences-LIPI, Cibinong, West Java, Indonesia. Living cultures were deposited at the 
LIPIMC microbial culture collection, Microbiology Division, Research Center for Biology, Indonesian Institute of Sciences-LIPI, Cibinong, West Java, Indonesia. Fungal species found in this study were compared to isolate of the M. eumusae, $M$. fijiensis, and M. musicola obtained from CBS culture collection (Table 1).

\section{DNA extraction and sequencing}

DNA from fungal cultures was extracted using cetyltrimethylammonium bromide (CTAB) protocols (Rogers \& Bendich 1994). The primers ITS1 (5'-GAAGTAAAAG TCGTAACAAG-3') and ITS4 (5'- CCTCCGCT'TATTGATATGC-3') (White et al. 1990) were used to amplify the ITS area. The PCR reaction mixture contained $5 \mu \mathrm{L}$ DNA suspension; $2.5 \mu \mathrm{L}$ of $10 \times$ concentrated reaction buffer containing $1.5 \mathrm{mM}$ $\mathrm{MgCl}_{2} ; 2.5 \mu \mathrm{l} 600 \mu \mathrm{MdNTP} ; 0.25 \mu \mathrm{L}$ of each primer at $60 \mu \mathrm{M} ; 0.2 \mu \mathrm{L}$ Taq DNA polymerase $(5 \mathrm{U} / \mu \mathrm{L}) ; 0.25 \mu \mathrm{l}$ internal control, and was filled up with MilliQ water to a final volume of $25 \mu \mathrm{L}$. The PCR reaction was performed as follows: 1 cycle of $5 \mathrm{~min}$ at $94^{\circ} \mathrm{C}$ followed by 40 cycles of $30 \mathrm{~s}$ at $94^{\circ} \mathrm{C}, 30 \mathrm{~s}$ at $52^{\circ} \mathrm{C}$, and $30 \mathrm{~s}$ at $72^{\circ} \mathrm{C}$. One cycle of $7 \mathrm{~min}$ at $72^{\circ} \mathrm{C}$ was conducted. After amplification, $5 \mu \mathrm{L}$ of the reaction mixture was loaded onto a $1.0 \%$ agarose gel in $0.5 \times \mathrm{TBE}$ buffer, separated by electrophoresis, stained with ethidium bromide, and viewed and photographed under UV light. A negative control (no DNA target) was included in every experiment to test for contamination, as well as a positive control (DNA from a reference strain of the pathogen). The amplicons was sequenced in both directions using the PCR primers and a DYEnamic ET Terminator Cycle Sequencing kit (Amersham, Biosciences) according to the manufacturer's recommendations. The products were analyzed on an ABI Prism 3700 DNA Sequencer (Perkin-Elmer, Foster City, CA). A consensus sequences were computed from the forward and reverse sequences with SeqMan from the Lasergene package (DNAstar, Madison, WI).

\section{Sequence alignment and phylogenetic analysis}

The sequences obtained from the respective primers (ITS5 and ITS4) were aligned in Clustal X (Thomson et al. 1997) and Bioedit (Hall 1999). Phylogenetic analysis was performed in PAUP* (Swofford 2002). Ambiguously aligned sites were excluded from all analyses. Unweighted parsimony (UP) analysis were performed. Gaps were treated as missing data. Maximum parsimony analysis was performed for all data sets using the heuristic search option with 1000 random taxa additions and tree bisection and reconstruction as the branch-swapping algorithm. Branches of zero length was collapsed and all multiple, equally parsimonious trees were saved. The robustness of the trees obtained was evaluated by 1,000 bootstrap replications. Other measures calculated include tree length, consistency index, retention index, and rescaled consistency index (TL, CI, RI, and RC, respectively). The resulting phylogenetic tree was printed with TreeView version 1.6.6 (Page 1996).

\section{Restriction Fragment Length Polymorphism (RFLP) analysis}

Restriction digestion of PCR products was conducted directly without further purification with restriction endonucleases to obtain RFLPs; each sample was digested 
with AluI, HaeIII, TaqI, or RsaI in single enzyme digests. Per each $20 \mathrm{~mL}$ restriction digest, $10 \mathrm{~mL}$ of unpurified, amplified PCR reaction was mixed with the appropriate restriction reaction buffer and $10 \mathrm{U}$ of the appropriate enzyme and then incubated for 6h at $37^{\circ} \mathrm{C}$ for the AluI, HaeIII, or RsaI digests or at $65^{\circ} \mathrm{C}$ for the Taq $\mathrm{I}$ digests. Restriction fragments were separated by electrophoresis in $2 \%$ (wt/vol) and $2.5 \%$ (wt/vol) Sepharide Gel Matrix in 1× TAE (40mM Tris acetate, $1 \mathrm{mM}$ sodium EDTA) with EtBr at $100 \mathrm{ng} / \mathrm{mL}$ in the gel and running buffer. DNA bands were visualized by fluorescence under UV light and photographed.

\section{Development of specific PCR primers}

Sequences obtained from ITS region were aligned with Clustal X (Thomson et al. 1997) dan Bioedit (Hall 1999). A series of species specific primers were designed using Vector NTI software (Invitrogen, Sigma-Aldrich), based on sequence differences among the $M$. fijiensis, $M$. musicola, and $M$. eumusae. The robustness and specificity of various primer combinations were evaluated using DNA from isolates of the $M$. fijiensis, $M$. musicola, and $M$. eumusae. DNA extraction and PCR amplification of these isolates were performed as described above.

Table 1. List of Mycosphaerella and Pseudocercospora obtained in this study.

\begin{tabular}{clll}
\hline No. & Name & Origin & $\begin{array}{l}\text { Culture Collection } \\
\text { Number }\end{array}$ \\
\hline 1 & $\begin{array}{l}\text { Mycosphaerella musicola } \\
\text { (Mycosphaerella sp.1) }\end{array}$ & $\begin{array}{l}\text { Cibinong, West Java, } \\
\text { Indonesia }\end{array}$ & LIPIMC 0598 \\
2 & $\begin{array}{l}\text { Mycosphaerella fijiensis } \\
\text { (Mycosphaerella sp. })\end{array}$ & Cibalagung, West & LIPIMC 0599 \\
3 & Mycosphaerella musicola & Java, Indonesia & \\
& (Mycosphaerella sp.3) & Wonosobo, Central & LIPIMC 0600 \\
4 & Mycosphaerella eumusae & Java, Indonesia & \\
5 & Mycosphaerella fijiensis & Unknown & CBS 114825 \\
6 & Mycosphaerella musicola & Cameroon & CBS 120258 \\
7 & Pseudocercospora sp. & Cuba & CBS 116634 \\
& & Cibinong, West Java, & LIPIMC 0601 \\
\hline
\end{tabular}

\section{RESULTS AND DISCUSSIONS}

\section{Fungal materials and phylogenetic analysis}

Three isolates of Mycosphaerella and one isolate of Pseudocercospora were isolated from specimens collected. The cultures of Mycosphaerella species collected in this study were compared morphologically to the three Mycosphaerella species from banana obtained from CBS culture collection (Netherlands). All isolates are listed in Table 1. BLAST result from NCBI GenBank database showed that sequences of Mycosphaerella sp.1 has 100\% similarity to the M. musicola (AY646445) (Fig. 1), and Mycosphaerella sp.2 has 99\% similarity to the M. fijiensis (Gq169763) (Fig. 2). 
The alignment data matrix of newly ITS sequences of three Mycosphaerella species and one Pseudocercospora Speg. species from banana were aligned with sequences of Mycosphaerella, Cercospora Fresen., Pseudocercospora and Passalora Fr. retrieved from NCBI GenBank DNA database. The alignment consists of 47 taxa including sequences of Cladosporium cladosporioides (Fresen.) G.A. de Vries and Davidiella tassiana (De Not.) Crous \& U. Braun as outgroup. The data matrix yielded 510 total characters included in the analysis of which 320 characters were constant, 27 characters were variable and parsimony-uninformative and 137 characters were parsimony-informative. Twentysix of the informative characters which were positioned within small insertion/deletions or ambiguous regions were excluded from the analysis. Two maximum parsimonious trees were generated from the analysis. Sum of minimum possible lengths is 232, and sum of maximum possible length was 1091. The best parsimonious tree selected by using $\mathrm{KH}$ test was generated in 360 steps $(\mathrm{CI}=0.644$, $\mathrm{RI}=0.851, \mathrm{RC}=0.548, \mathrm{HI}=0.356)$. The best phylogenetic trees obtained from unweighted maximum parsimony analysis is shown in Figure 3.
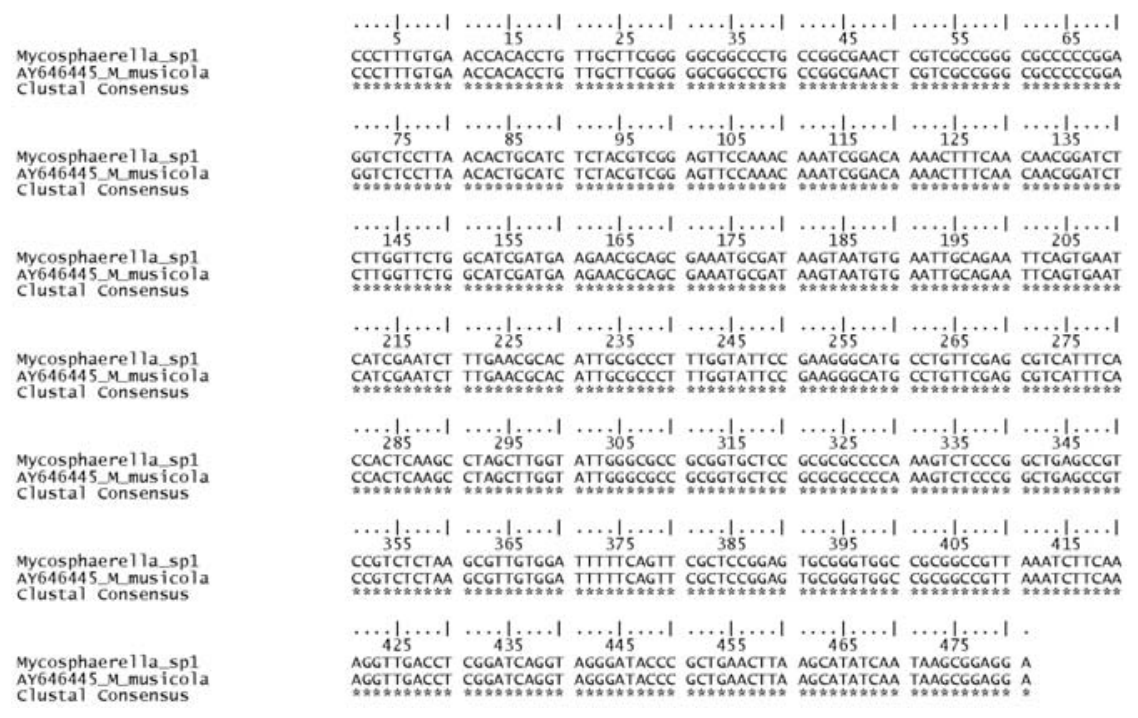

Figure 1. Pairwise alignment showed 100\% similarity between Mycosphaerella sp.1 and $M$. musicola (Ay646445).

Based on this analysis, three major clades were performed. These included Mycosphaerella clade with Psendocercospora anamorph (Clade I) with 61\% bootstrap support. Another clade was Mycosphaerella and Cercospora anamorph (Clade II, 54\% bootstrap support) which is also sister clade to Mycosphaerella-Psendocercospora clade with 61\% bootstrap support. The last clade is Mycosphaerella and Passalora anamorph (Clade III) with $90 \%$ bootstrap support. The Mycosphaerella sp.1 from this study nested together with species in the M. musicola clade with 100\% bootstrap support. Another Mycosphaerella species from this study, Mycosphaerella sp.3 nested together with species within $M$. fijiensis clade with $92 \%$ bootstrap support. This information confirms the 
species name of Mycosphaerella sp.1 as M. musicola, and Mycosphaerella sp.3 as M. fijienssis. Furthermore, this finding confirms that $M$. fijiensis and $M$. musicola exist in Indonesian banana plantation (Java). Another isolate, Pseudocercospora sp.1 needs more detailed examination as this species does not form monophyletic group with any clades in the phylogenetic tree. All Mycosphaerella species from banana, viz, M. eumusae, M. fijiensis, and $M$ musicola form a monophyletic clade with $52 \%$ bootstrap support. This finding has shown that Mycosphaerella species from banana is a distinct group of species among the Mycosphaerella species from various hosts. It has also indicated that the three species of Mycosphaerella from banana are host specific to the banana trees. Further analysis such as pathogenicity test is necessary to carry out in order to justify the specificity of the three Mycosphaerella species from banana.

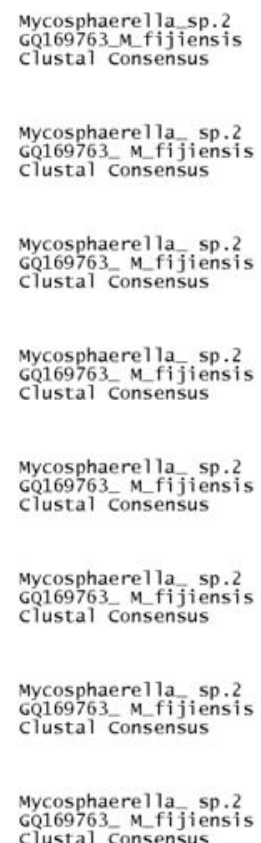

Figure 2. Pairwise alignment showed two nucleotides differences between Mycosphaerella sp.2 and M. fijiensis (GQ169763) (boxes)

\section{Restriction Fragment Length Polymorphism (RFLP) analysis}

Polymorphism of fragment size of ITS regions was recognized as reported previously in other fungal group (Gardes \& Bruns 1993; Sreenivasadprasad et al. 1996), and it was thought to be variable in the sequences of ITS region because of nucleotide deletions and insertions. In order to identify the Mycosphaerella species detected by PCR using primers ITS 5 and ITS4, the RFLPs of the ITS region were generated using four restriction enzymes, namely, AluI, HaeIII, TaqI, or RsaI. From the analysis, only RsaI was not very useful because it did not cut the amplicon of all Mycosphaerella species 
from banana (Fig. 4a). Other restriction enzymes, namely, AluI, HaeIII, and TaqI, generated more fragment per digest, so that the ITS sequences of the Mycosphaerella fijiensis, M. musicola, and M. eumusae could be separated using each RFLPs profile. The HaeIII had two recognition sites in the fragments of $M$. eumusae, and had three recognition sites in the fragments of M. musicola and M. fijiensis (Fig. 4b). One isolate of M. musicola can also be separated from three other isolates of M. musicola using the HaeIII restriction enzyme because it only had two recognition sites in the fragments. A similar result was also found in the restriction fragments of $M$. musicola generated by $A l u \mathrm{I}$ and TaqI (Fig. 4c-d). The majority of RFLPs profiles generated from HaeIII were unique for each Mycosphaerella species. For M. musicola, the given enzymes (AluI and TaqI) probably generated RFLPs profiles which separated isolates at the subspecies level (Fig. 4c-d), but further analysis will be required to justify this result.

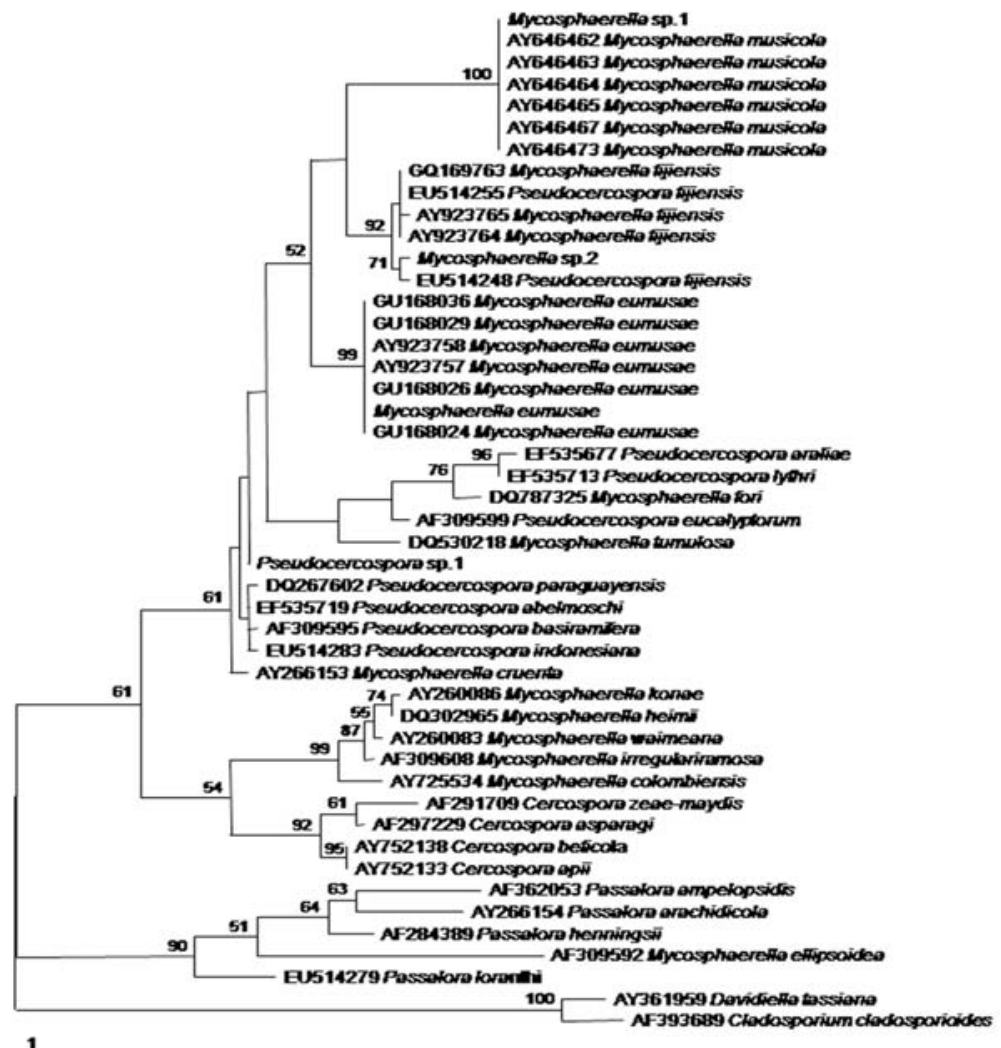

Figure 3. Single parsimonious tree based on ITS nrDNA sequence data representing placement of Mycosphaerella spp. and Pseudocercospora sp.1 found in this study within representatives of the family Mycosphaerellaceae. The tree is obtained from heuristic search with 1000 random taxon addition of the sequences alignment. Bootstrap values $(>50 \%)$ from 1000 replicates of Unweighted Maximum Parsimony (UMP) analyses are shown above internodes. 


\section{Development of Specific PCR Primers}

Understanding the banana Sigatoka disease complex is a challenge for plant pathologists (Arzanlou et al. 2007). Therefore, in this study we developed rapid and specific detection method with the feasibility of wide application. Even though a PCR-based detection tool has been developed previously (Johanson \& Jeger 1993), those primers could only differentiate $M$. fijiensis from $M$. musicola. Three speciesspecific primers were designed, namely, MeuF/MeuR, MfijF/MfijR, and MmusF/MmusR, respectively (Table 2). All primers were designed to operate at relatively high annealing temperatures $\left(54^{\circ} \mathrm{C}-55^{\circ} \mathrm{C}\right)$, thereby preventing the coamplification of non-specific DNA targets. Primer sequences were compared against existing sequences in NCBI GenBank Data Base (http://www.ncbi.nlm.nih.gov/) and DDBJ DNA Data Base of Japan (http://www.ddbj.nig.ac.jp/), and a result of BLAST (Basic Local Alignment Search Tool) showed 100\% homology of the primers with sequences of strains belonging to the species of which primers were designed. Single bands of correct size were obtained with species-specific primers from all strains belonging to the three Mycosphaerella species from banana.

Table 2. Primer pairs designed in this study.

\begin{tabular}{|c|c|c|c|}
\hline No. & Name & Species target & Notes \\
\hline 1 & $\begin{array}{l}\text { MeuF (Forward) } \\
\text { (5'-CATCTTTGCGTCGGAGTTCA-3') } \\
\text { MeuR (Reverse) } \\
\text { (5'-CCGAAGCGAATTGGAAGAATCC-3') }\end{array}$ & Mycosphaerella eumusae & $\begin{array}{l}\text { Not species-specific } \\
\text { (cross reactions with } \\
\text { M. fijiensis) }\end{array}$ \\
\hline 2 & $\begin{array}{l}\text { MfijF (Forward) } \\
\text { (5'-TCT'T'TGCGTCGGAGT'TTCA-3') } \\
\text { MfijR (Reverse) } \\
\text { (5'-TCCGAAGCGAATTGAAAGATC-3') }\end{array}$ & Mycosphaerella fijiensis & Species-specific \\
\hline 3 & $\begin{array}{l}\text { MmusF (Forward) } \\
\text { (5'-TCCTTAACACTGCATCTCTACG-3') } \\
\text { MmusR (Reverse) } \\
\text { (5'-TCAGCCGGGAGACTTTGG-3') }\end{array}$ & Mycosphaerella musicola & Species specific \\
\hline
\end{tabular}

Validation assay on pure cultures of $M$. eumusae, $M$. fijiensis, and $M$. musicola showed that primer pairs of $M$. fijiensis (MfijF/MfijR) (Fig. 5a) and $M$. musicola (MmusF/MmusR) (Fig. 5b) are specific to the fungal pathogens as no cross-reactions with others Mycosphaerella species were observed in the amplification bands. Unfortunately, primer pairs of $M$. eumusae (MeuF/MeuR) failed to show specificity as cross-reactions were found with sequences of $M$. fijiensis (Fig. 5c). It is probably due to small nucleotide differences between DNA sequences $M$. eumusae and M. fijiensis from ITS region. The specificity of primer pairs of MfijF/MfijR to $M$. fijiensis and MmusF/MmusR to M. musicola is good indication for the development of molecular diagnosis technique and understanding of the Sigatoka diseases complex of banana in Indonesia. The molecular technique developed in this study may also significantly contribute to plant quarantine because of its reliability, specificity and simplicity. This assay could be done within 1-2 days laboratory works and analysis. 
PCR assay based on the ITS regions for identification of Mycosphaerella species on Banana - Iman Hidayat

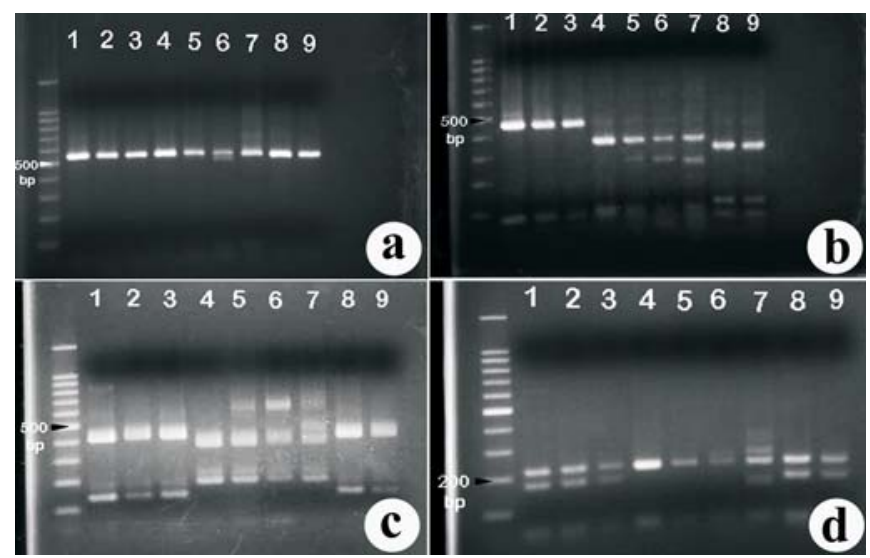

Figure 4. Restriction patterns of internal transcribed spacer (ITS) regions of ribosomal DNA amplified from three Mycosphaerella species from banana. a. RsaI b. HaeIII c. AluI d. TaqI (1-3: M. eumusae; 4-7: M. musicola; 8-9: M. fïiensis).

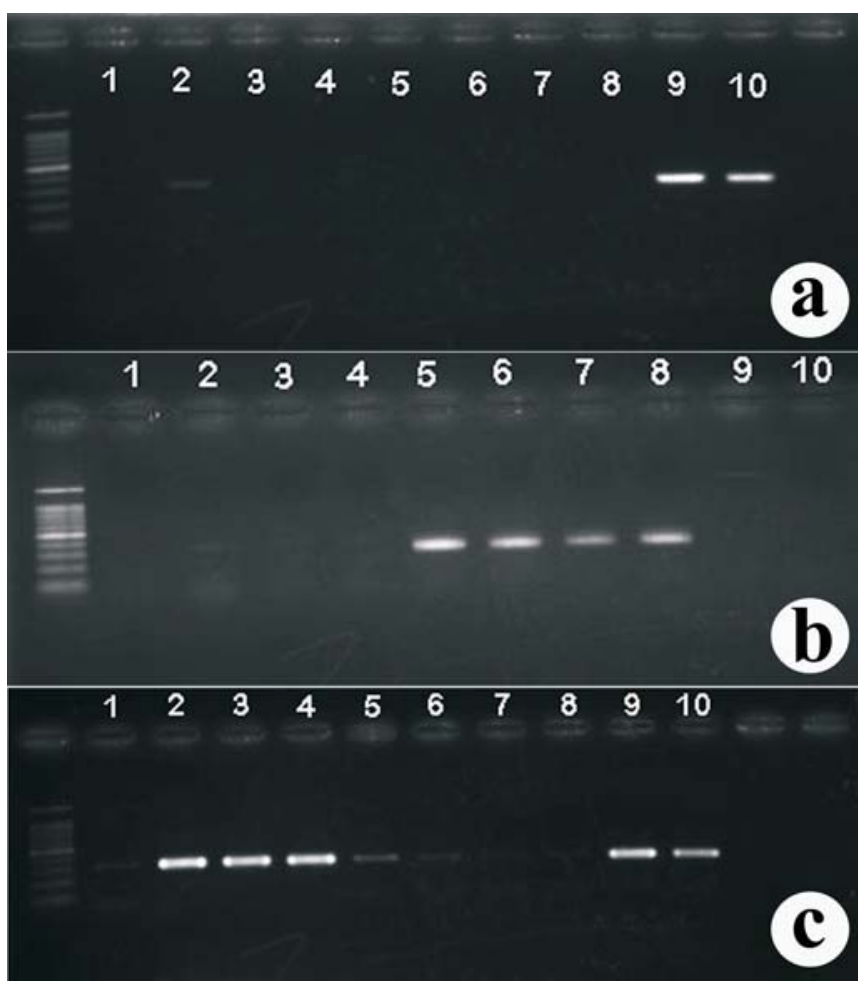

Figure 5. Species-specific amplification of Mycosphaerella species from banana using specific primers. a. Primer pairs $\mathrm{MfijF} / \mathrm{Mfij} \mathrm{R}$ to the $M$. fijiensis b. primer pairs MmusF/MmusR to the M. musicola c. primer pairs MeuF/MeuR to the M. eumusae and M. fijiensis (2-4: M. eumusae; 5-8: M. musicola; 9-10: M. fijiensis). 


\section{CONCLUSIONS}

Diagnosis of the banana Sigatoka disease complex is a challenge for plant pathologists. RFLP analysis using HaeIII restriction ensyme is capable in discriminating the $M$. eumusae, $M$. fijiensis, and $M$. musicola. The rapid and specific PCR-based detection method using species-specific primers of MfijF/MfijR and MmusF/MmusR has been successfully developed to detect $M$. fijiensis and $M$. musicola, respectively, from pure cultures. Further examination/validation directly on samples from infected banana leaves with Mycosphaerella diseases symptom are necessary to test the sensitiveness of this method.

\section{ACKNOWLEDGMENTS}

This research was funded by SEAMEO BIOTROP awarded to Dr. Iman Hidayat. Laboratory of Plant Molecular Systematics, Botanical Division, Research Center for Biology (LIPI) is acknowledged for providing the authors with molecular facilities. The author also thanks Sulistiani and Aerma Hastuty for laboratory assistance.

\section{REFERENCES}

Arzanlou M, Abeln ECA, Kema GHJ, Waalwijk C, Carlier J, de Vries I, Guzmán M, Crous PW. 2007. Molecular diagnostics for the Sigatoka disease complex of banana. Phytopathology 97:1112-8.

Bonants P, Hagenaar-deWeerdt M, van Gent-Pelzer M, Lacourt I, Cooke D, Duncan J. 1997. Detection and identification of Phytophthora fragariae Hickman by the polymerase chain reaction. Eur J Plant Pathol 103: 345-55.

Choi YW, Hyde KD, Ho WH. 1999. Single spore isolation of fungi. Fungal Divers 3: 29-38.

Crous PW, Mourichon X. 2002. Mycosphaerella eumusae and its anamorph Pseudocercospora eumusae spp. nov.: causal agent of eumusae leaf spot disease of banana. Sydowia 54: 35-43.

Crous PW, Groenewald JZ, Aptroot A, Braun U, Mourichon X, Carlier J. 2002. Interacting morphological and molecular data sets on Mycosphaerella with specific reference to species occurring on Musa. In: Jacome L, Lepoivre P, Marin D, Romero R, Escalant JV, editors. Proceedings of the $2^{\text {nd }}$ International workshop on Mycosphaerella leaf spot diseases. San Jose, Costa Rica. p 43-57.

Gardes M, Bruns TD. 1993. ITS primers with enhanced specificity for basidiomycetes - application to the identification of mycorrhizae and rusts. Mol Ecol 2:113-8.

Hall TA. 1999. BioEdit: a user-friendly biological sequence alignment editor and analyses program for Windows 95/98/NT. Nucleic Acids Symposium Series 41: 95-98.

Hidayat I, Meeboon J, To-anun C. 2007. Anthostomella and Fasciatispora species (Xylariaceae) from palms including F. ujungkulonensis sp. nov. Mycotaxon 102:347-54.

Johanson A, Jeger MJ. 1993. Use of PCR for detection of Mycosphaerella fijiensis and M. musicola, the causal agents of Sigatoka leaf spot in banana and plantain. Mycol Res 97: 670-74.

Mumford R, Boonham N, Tomlinson J, Barker I. 2006. Advances in molecular phytodiagnostics - new solutions for old problems. Eur J Plant Pathol 116:1-19.

Page RDM. 1996. TreeView, an application to display phylogenetic trees on personal computers. Comput Appl Biosci 12: 357-58. 
PCR assay based on the ITS regions for identification of Mycosphaerella species on Banana - Iman Hidayat

Rogers SO, Bendich AJ. 1994. Extraction of total cellular DNA from plant,algal, and fungal tissues. Pp. Dl. 1-8. In : Gelvin S, Schilperoort RA, editor. Plant molecular biology manual. $3^{\text {td }}$ edition. Kluwer Academic Publishers, Boston. Massachusetts, USA.

Sreenivasadprasad S, Mills PR, Meehan BM, Brown AE. 1996. Phylogeny and systematics of 18 Colletotrichum species based on ribosomal DNA spacer sequences. Genome 39: 499-512.

Swofford DL. 2003. PAUP*: Phylogenetic analyses using parsimony (* and other methods), version $4.0 \mathrm{~b} 10$. Sinauer Associates, Sunderland, Massachusetts.

Thomson JD, Gibson TJ, Plewniak F, Jeanmougin F, Higgins DG. 1997. The Clustal_X windows interface: Flexible strategies for multiple sequences alignment aided by quality analyses tools. Nucleic Acids Res 25: 4876-82.

White TJ, Burns T, Lee S, Taylor J. 1990. Amplification and direct sequencing of fungal ribosomal RNA genes for phylogenetics. In: Innis MA, Gelfand DH, Sninsky JJ, White TJ, editors. PCR Protocols: a Guide to Methods and Application. Academic Press, San Diego. P 315-22. 